\title{
Is Global Warming All about Technological Issues?
}

\author{
Jan-Erik Lane ${ }^{1^{*}}$ \\ ${ }^{1}$ Fellow at the Public Policy Institute, Belgrade; 10 Charles Humbert, 1205 Geneva; 559 A, 3rd Floor, \\ Thuya Street, 9th Quarter, Yangon, Myanmar \\ *Jan-Erik Lane, E-mail: janeklane@gmail.com \\ Received: October 18, 2016 Accepted: October 21, 2016 Online Published: October 21, 2016 \\ doi:10.22158/wjssr.v3n4p495 \\ URL: http://dx.doi.org/10.22158/wjssr.v3n4p495
}

\begin{abstract}
When the COP21 project is analysed with economic and social science models, then one arrives at profound pessimism about the prospects of implementation success. The basic Wildavsky gulf between policy promises and real life implementation outcomes is bound to plague the efforts at coordination to halt the climate change process. The natural sciences have dominated the global warming debate, but it is time to start examining the problematic of delivering great transformation of energy systems to stem the anthropogenic causes of global warming through the emission of greenhouse gases (GHG). The erection of the Super Fund is a necessity for avoiding decision paradoxes like PD games, sub-optimisation and second best solutions. Without massive financial assistance, there will occur widespread reneging on the COP21 objectives (Goal I-III). The system of United Nations Climate Change Conferences, yearly conferences held in the framework of the United Nations Framework Convention on Climate Change (UNFCCC), does not offer an organization that is up to the coordination tasks involved in halting climate change.
\end{abstract}

\section{Keywords}

climate change, natural science problematics, social sciences' paradoxes, stochastic Kaya model, emissions plus energy and GDP links, country predicaments, Super Fund

\section{Introduction}

It is true that climate change and its implications are given much more attention now, after the COP21 Agreement in Paris. There are almost weekly conferences about global warming and the debate is intense all over the globe. This is a positive, but one must point out the exclusive focus upon natural science and technological issues, which actually bypasses the thorny problems of international governance and the coordination of states. The social science aspects of global warming policy-making will be pointed out in this article. This is a problematic by itself that reduces the likelihood of successful implementation of the goals of the COP21 Agreement (Goal I, Goal II and Goal III in global decarbonistion). 


\section{The Enigmatic Issues in Climate Change}

It is quite understandable that the focus in all the international conferences, some of which are now speaking of COP22 meetings, is upon the natural science issues in climate change. They deal with how dangerous the global warming process could be as well as the feasibility of halting this trend in the 21 rdt century by various measures, like for instance carbon capture. Yet, by neglecting some very relevant social science models, the COP21 approach of decarbonisation will run into major difficulties, already in the next decade. Can really international governance together with states coordination deliver policies and will they be implemented in a decentralized approach? This question is most relevant, even when the natural sciences and technology arrives at conclusive answers to the major issues in climate change.

It seems to me that the key issues in the global climate change debate concerns inter alia the following: 1. What more precisely is the link between the amount of carbon in the atmosphere and the rise of temperature, in sea and $\mathrm{n}$ land? Is it a linear or non-linear link? Thresholds? Reversibility?

2. How and when will rising temperatures in sea and at land affect basic environmental aspects, like the ice layers and the frozen waters as well as glaciers?

3. How much carbon will be stocked in the atmosphere in this century, given alternative scenarios of emissions and natural carbon uptake? How dangerous could increasing GHG:s like methane be?

4. Is it at all feasible to accomplish massive decarbonisation of the air by means of carbon sequestration at what costs?

Having full knowledge about all these issues would improve much upon the theories of global warming and would be extremely useful in practice when policies are to me made about decarbonisation.

Yet, they do not comprise the implications of lessons of the social sciences for global governance, coordination and policy making. The crux of the matter is what I call the Wildavsky hiatus: policies however appealing are bound to fail when put in practice, as no policy is self-implementable (Pressman \& Wildavsky, 1973, 1984). To grasp the feasibility of the COP21 project and its three goals of decarbonisation, one must understand the implementation deficit and the coordination failures. I will spell out these concepts here in relation to the COP21 framework, and its three objectives, namely:

a) Halting the increase in carbon emission up to 2020 (Goal I);

b) Reducing CO2:s up until 2030 with 40 per cent (Goal II);

c) Achieve more less total decarbonisation until 2075 (Goal III).

It is up to the governments of the countries to implement these goals with rather weak overview from international governance but with the promise of assistance from a huge Super Fund. What, then, are the INCENTIVES involved in decentralised decarbonisation a la COP21? To discuss decarbonisation feasibility along the three goals - Goal I, Goal II and Goal III-one need to take into account the restrictions on human action and interaction in social systems, spelled out in economic theory and game theory. 


\section{Economic Restriction: The Kaya Model}

The basic theoretical effort to model the greenhouse gases, especially $\mathrm{CO} 2 \mathrm{~s}$, in terms of a so-called identity is the deterministic Kaya equation. The Kaya identity, "I = PAT"-model type, describes environmental (I)mpact against the (P)opulation, (A)ffluence and (T)echnology. Technology covers energy use per unit of GDP as well as carbon emissions per unit of energy consumed (Kaya \& Yokoburi, 1997).

\subsection{Theory}

In theories of climate change, the focus is upon so-called anthropogenic causes of global warming through the release of greenhouse gases (GHG). To halt the growth of the GHG:s, of which CO2:s make up about 70 per cent, one must theorize the increase in $\mathrm{CO} 2$ :s over time (longitudinally) and its variation among countries (cross-sectionally). As a matter of fact, $\mathrm{CO} 2$ :s have very strong mundane conditions in human needs and social system prerequisites. Besides the breading of living species, like Homo sapiens for instance, energy consumption plays a major role. As energy is the capacity to do work, it is absolutely vital for the economy in a wide sense, covering both the official and the unofficial sides of the economic system of a country. The best model of carbon emissions to this day is the so-called Kaya model. It reads as follows in its standard equation version-Kaya's identity:

(E1) Kaya's identity projects future carbon emissions on changes in Population (in billions), economic activity as GDP per capita (in thousands of \$US(1990)/person year), energy intensity in Watt years/dollar, and carbon intensity of energy as Gton $\mathrm{C}$ as $\mathrm{CO}_{2}$ per TeraWatt year" (http://climatemodels.uchicago.edu/kaya/kaya.doc.html).

Concerning the equation (E1), it may seem premature to speak of a law or identity that explains carbon emissions completely, as if the Kaya identity is a deterministic natural law. It will not explain all the variation, as there is bound to be other factors that impact, at least to some extent. Thus, it is more proper to formulate it as a stochastic law-like proposition, where coefficients will be estimate using various data sets, without any assumption about stable universal parameters. Thus, we have this equation format for the Kaya probabilistic law-like proposition, as follows:

(E2) Multiple Regression: $Y=a+b_{1} X_{1}+b_{2} X_{2}+b_{3} X_{3}+\ldots+b_{t} X_{t}+u$

Note: $\mathrm{Y}=$ the variable that you are trying to predict (dependent variable); $\mathrm{X}=$ the variable that you are using to predict $\mathrm{Y}$ (independent variable); $\mathrm{a}=$ the intercept; $\mathrm{b}=$ the slope; $\mathrm{u}=$ the regression residual. Note: http://www.investopedia.com/terms/r/regression.asp\#ixzz4Mg4Eyugw

Thus, using the Kaya model for empirical research on global warming, the following anthropegenic conditions would affect positively carbon emissions:

(E3) $\mathrm{CO} 2 \mathrm{~s}=\mathrm{F}(\mathrm{GDP} /$ capita, Population, Energy intensity, Carbon intensity), in a stochastic form with a residual variance, all to be estimated on data from some 59 countries. I make an empirical estimation of this probabilistic Kaya model-the cross-sectional test for 2014:

(E4) $\mathrm{k} 1=0,68, \mathrm{k} 2=0,85, \mathrm{k} 3=0,95, \mathrm{k} 4=0,25 ; \mathrm{R} 2=0,895$. 
Note: $\mathrm{LN} \mathrm{CO} 2=\mathrm{k} 1 * \mathrm{LN}(\mathrm{GDP} / \mathrm{Capita})+\mathrm{k} 2 *($ dummy for Energy Intensity $)+\mathrm{k} 3 *$ (LN Population) $+\mathrm{k} 4 *$ (dummy for Fossil Fuels/all) Dummy for fossils 1 if more than $80 \%$ fossil fuels; 44 not significantly proven to be non-zero, all others are $(\mathrm{N}=59)$.

The Kaya model findings show that total GHG:s go with larger total GDP. To make the dilemma of energy versus emissions even worse, we show in Figure 1 that GDP increase with the augmentation of energy per capita. Decarbonisation is the promise to undo these dismal links by making GDP and energy consumption rely upon carbon neutral energy resources, like modern renewables and atomic energy.

GDP vs. Energy usage per capita $1990-2014$
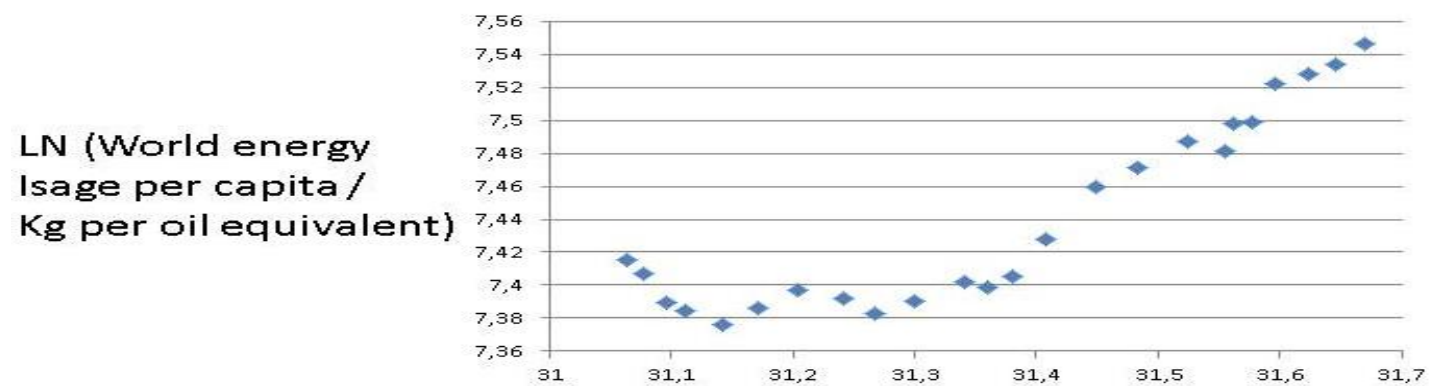

LN (World GDP in constant value 2005 USD) Figure 1. GDP against Energy per Person (All Countries)

We need to model this energy-emission dilemma for the countries of the COP21 project. To understand the predicament of Third World countries, we need to know whether GHC:s or CO2:s are still increasing (Goal I) and what the basic structure of the energy mix is (Goal II). Thus, I suggest:

"GDP-GHG(CO2) link, energy mix", as a model of the decarbonisation feasibility in some Third World countries, to be analysed below, following the so-called "Kaya" model. The first concept taps the feasibility of Goal I: halting the growth of GHG:s or CO2:s, whereas the other concepts targets the role of fossil fuels and wood coal like charcoal.

The difference between global warming concern and general environmentalism appears clearly in the evaluation of atomic power. For reducing climate change, nuclear power is vital, but for environmentalism atomic power remains a threat. From a short-term perspective, the global warming concerns should trump the fear of radioactive dissemination, as global warming will hit mankind much sooner. In the Third World, nuclear power plants are increasing in number, whereas in the mature economies their number is being reduced. New nuclear technology is much safer, why also advanced countries should use this option, like for instance the UK.

Australia: Decarbonisation, only if economic growth

When one goes beyond the EU, one finds only two cases of declining GDP-COP curve: Australia and 
Japan. Japan has for a long time substituted coal for atomic power, although recently with a crucial set.

But Australia has always been the country of fossil fuels, exporting coal and iron in huge amounts. However, it has reached its $\mathrm{CO} 2$ peak recently (Figure 2).

GDP - CO2 for Australia 1990 - 2014

LN (CO2 Emissions / kg of oil equivalent)

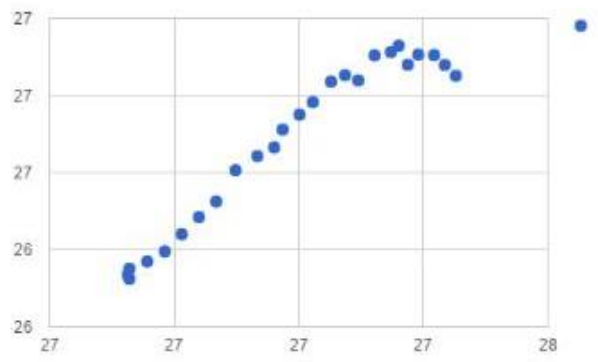

LN (GDP / Constant Value 2005 \$)

Figure 2. Australia

Exports Australia has been extremely dependent upon fossil fuels, domestically and in. Cutting back its coal dependency will allow the country to halt its $\mathrm{CO} 2$ emissions, while moving to renewables. The fossil fuel dependency of Australia is simply stunning (Figure 3).

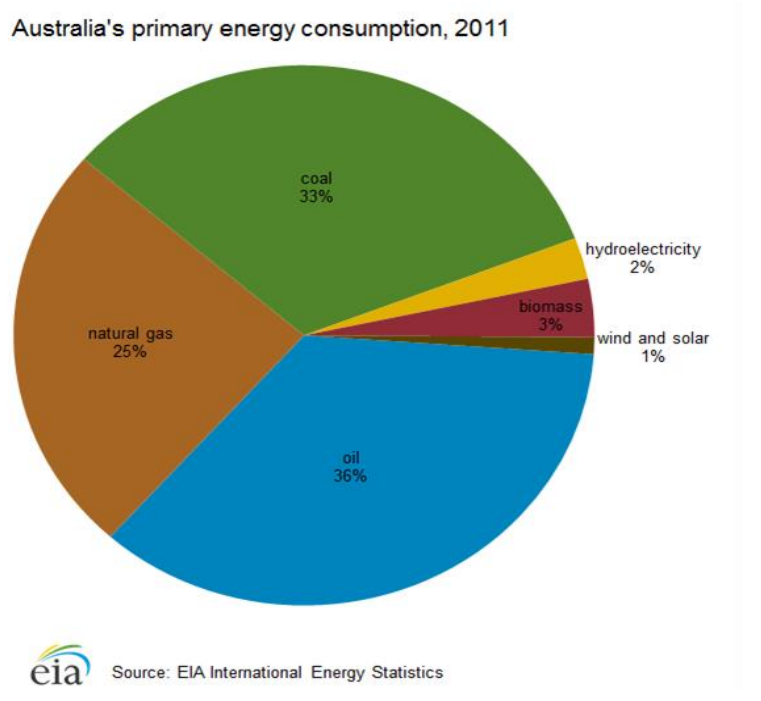

Figure 3. Energy Mix in Australia

Australia has often been accused of fuelling climate change. These accusations appear to be vindicated in the Figure above that shows an extreme reliance upon fossil fuels. Add then all the export of raw materials! One prime minister of Australia has declared that the country will reduce $\mathrm{CO} 2$ :s only if 
economic growth is not hurt. It remains to be seen how Australia tackles Goal I and Goal II. Former premier Abbott expressed an Australian preference: first growth, second decarbonisation.

\section{Game Theory Models: Coordination Failures}

Just because there is an agreement it does not entail it will be respected. Even if respecting the promises made is the best strategy for all partners to the dal, each individual has an incentive to renege upon the agreement. In two-person game theory, a few much discussed models portray coordination failures, and they are applicable to governments as well as international governance. If, as shown above with the Kaya model, decarbonisatin may be costly, hurting economic development, then perhaps a country may simply go its own way, leaving it up to the other(s) to handle the externalities in global warming. Why make costly contributions to collective action? Remember that small countries do not matter much (N-1 problematic) and huge countries would have to share the benefits with all others (I/N problematic).

The interaction between nations and their governments can be of two kinds: zero sum game or variable sum game. Halting the climate change process constitutes a Pareto optimal goal for all participants with means of collective action, coordination either by themselves or with a third party, an international governance body like that of the UNFCCC. However, coordination may fail to reach a set of Pareto optimal outcomes, as the choice participants chose Pareto inferior strategies due to self-interest seeking with guile. Coordination failures arise when individual rationality prevails over collective rationality:

- Reneging (PD game)

- $\quad$ Threat (Chicken game)

- Sub-optimality (Negotiation game)

- Second best solutions (Assurance game).

We will give some examples of these possible coordination failures in the management of the global warming process, where also financial help from a Super Fund enters the gaming strategies. Thus for instance, poor countries with huge total emissions may demand much larger reductions percentage wise from rich countries with high per capita emissions. Unless accepted, they renege upon the COP21 objectives of decarbonisation.

\section{Comparative Country Enquiry}

I will analyse a few important countries in a comparative fashion so that they can be compared systematically. Two diagrams will be presented for each country, related to the research approach above. First, the COP21 Goal I will be tapped by looking at the curve between GDP and CO2:s (GHG:s), whether is rising or declining and whether it slopes outward or inward. Second, the COP21 Goal II is enquired into, as the energy consumption mix is portrayed: the more reliance upon fossil fuels and charcoal, the more costly the energy transition. What matters in both diagrams are both absolute and 
relative numbers. Thus, the coal share of energy resources may go down, but if total energy consumed is up, emissions will remain at a high level.

\subsection{Countries with Real Reneging Option (PD Games)}

A set of countries with huge population at a low level income per person will find the COP21 objectives too exigent. They have to plan for more of energy in order to strengthen economic development against widespread poverty amidst string population growth. These countries can only promote Goal I and Goal II, if supported by the Super Fund.

\subsubsection{India}

India will certainly appeal to the same problematic, namely per capita or aggregate emissions. The country is more negative than China to cut GHG emissions, as it is in an earlier stage of industrialization and urbanization. Figure 4 shows the close connection between emissions and GDP for this giant nation.

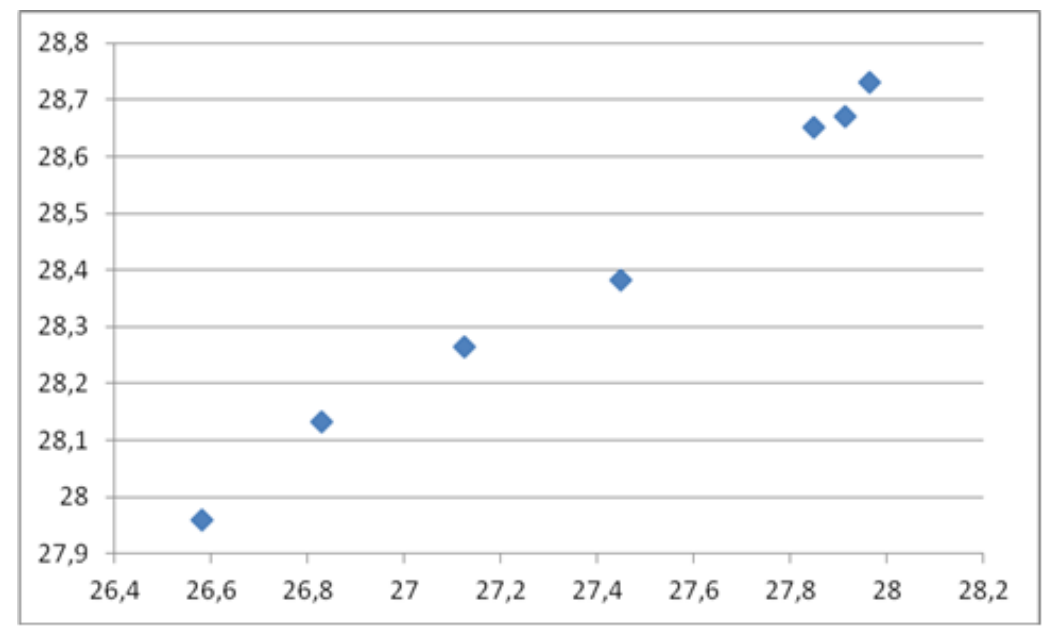

Figure 4. India: LN (GHG/Kg CO2 eq and LN (GDP/Constant Value 2005 USD))

Note. $\mathrm{GHG}=\mathrm{y}$-axis, $\mathrm{GDP}=\mathrm{x}$-axis.

India needs cheap energy for its industries, transportation and heating (Figure 6) as well as electrification. From where will it come? India has water power and nuclear energy, but relies most upon coal, oil and gas as power source. It has strong ambitions for the future expansion of energy, but how is it to be generated, the world asks. India actually has one of the smallest numbers for energy per capita, although it produces much energy totally. Figure 5 shows its energy mix where renewables play a bigger role than in for instance China. 


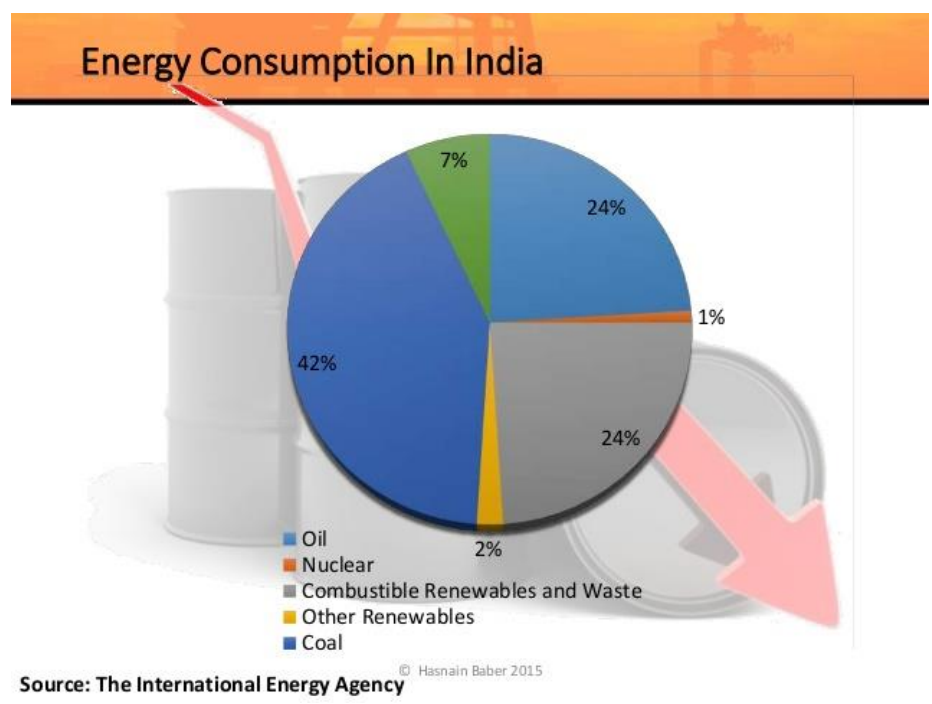

Figure 5. Indian Energy

India needs especially electricity, as 300 million inhabitants lack access to it. The country is heavily dependent upon fossil fuels (70 per cent), although to a less extent than China. Electricity can be generated by hydro power and nuclear power, both of which India employs. Yet, global warming reduces the capacity of hydro power and nuclear power meets with political resistance. Interestingly, India uses much biomass and waste for electricity production, which does not always reduce GHG emissions. India's energy policy will be closely watched by other governments and NGO:s after 2018.

\subsubsection{Indonesia}

One may guess correctly that countries that try hard to "catch-up" will have increasing emissions. This was true of China and India. Let us look at three more examples, e.g., giant Indonesia — now the fourth largest emitter of GHG:s in the world (Figure 6).

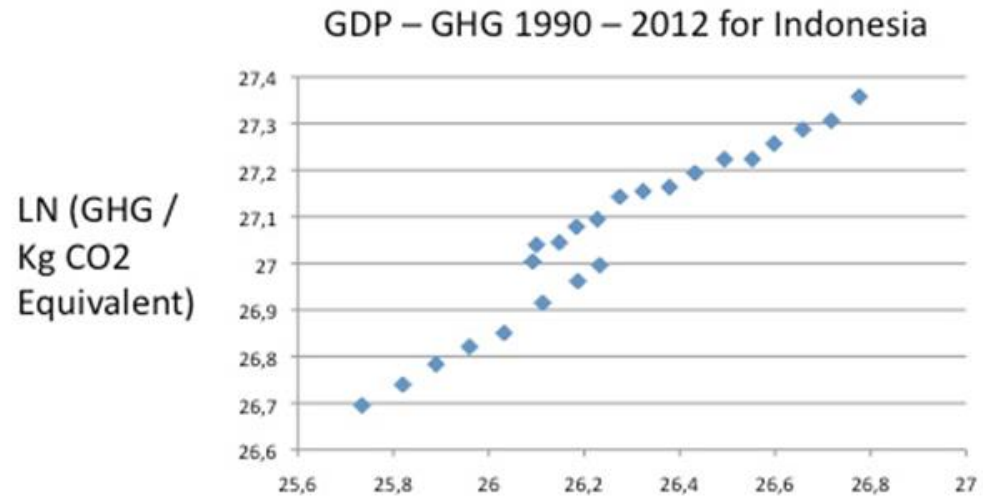

LN (GDP / Constant Value 2005 USD)

Figure 6. Indonesia: LN (GHG/Kg CO2 eq and LN (GDP/Constant Value 2005 USD)) 
Indonesia is a coming giant, both economically and sadly in terms of pollution. Figure 11 reminds of the upward trend for China and India. However, matters are even worse for Indonesia, as the burning of the rain forest on Kalimantan and Sumatra augments the GHG emissions very much. Figure 7 presents the energy mix for this huge country in terms of population and territory.

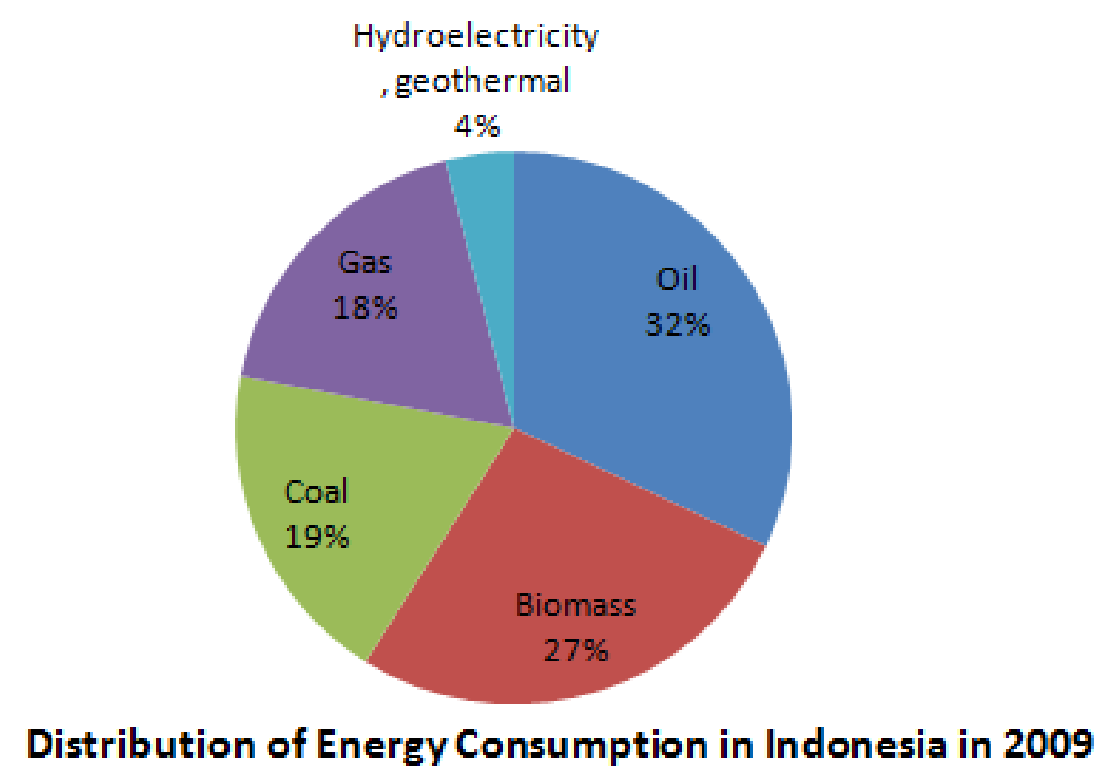

Figure 7. Indonesian Energy

Note. http://www.missrifka.com/energy-issue/recent-energy-status-in-indonesia.html

Only 4 per cent comes from hydro power with 70 per cent from fossil fuels and the remaining 27 per cent from biomass, which alas also pollutes.

\subsubsection{Pakistan}

The same upward trend for emissions holds for another major developing country with huge population, namely Pakistan (Figure 8). 


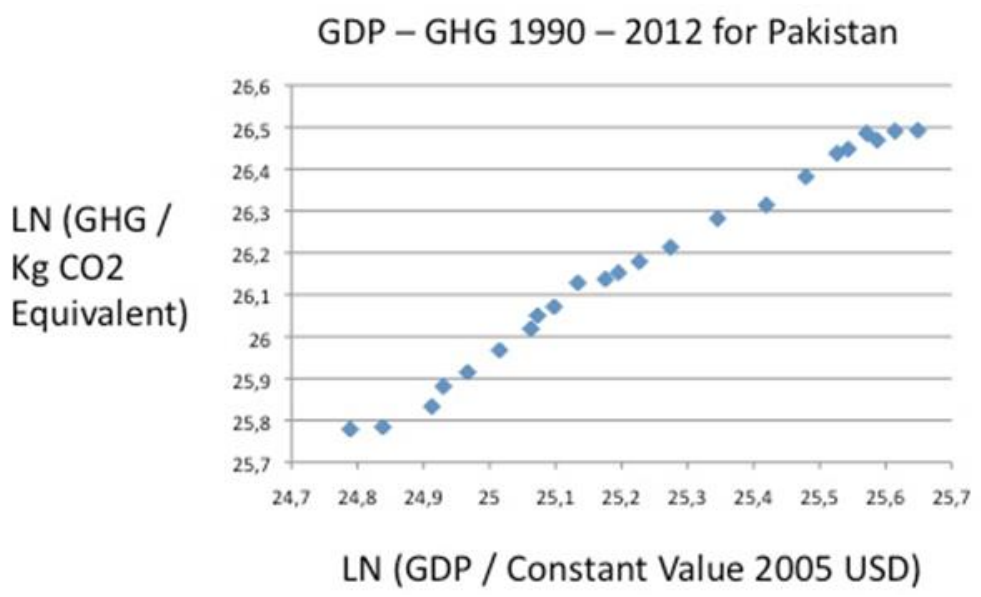

Figure 8. Pakistan: LN (GHG/Kg CO2 eq and LN (GDP/Constant Value 2005 USD))

The amount of GHG emissions is rather large for Pakistan, viewed on aggregate. Pakistan is mainly reliant upon fossil fuels (Figure 9).

PAKISTAN ENERGY CONSUMPTION

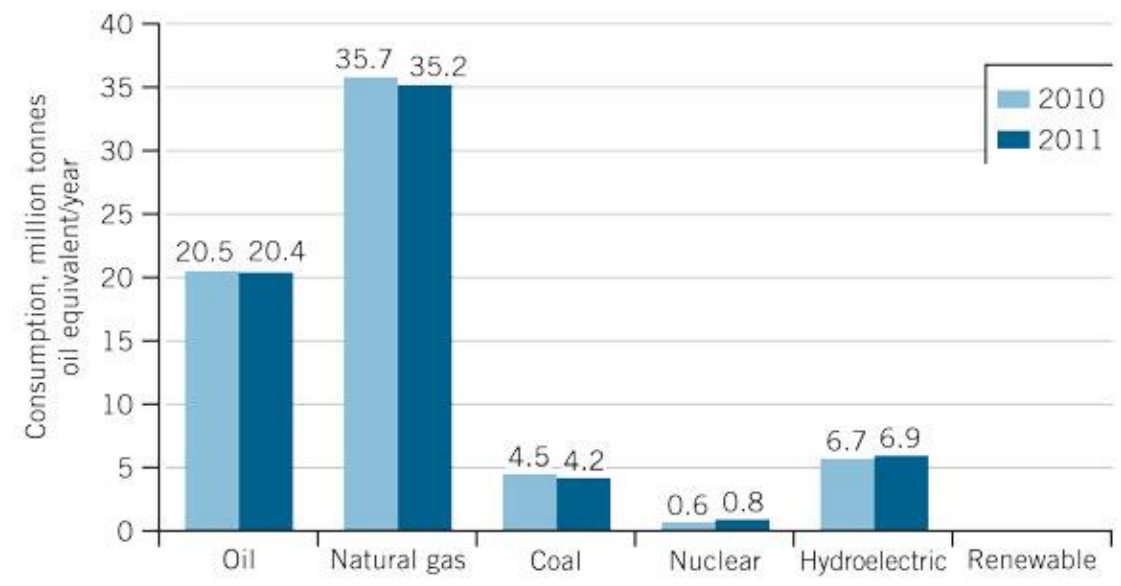

Source: BP Statistical Review of World Energy 2012
FIG 2

1,1"

Figure 9. Pakistan Energy

But Pakistan employs a considerable portion of hydropower-13 per cent-and a minor portion of nuclear power, which is a positive.

\subsubsection{Bangladesh}

Moving on to another giant nation in South Asia, Bangladesh, we find an entirely different set of conditions for implementing COP21. Figure 10 shows that the major GHC of $\mathrm{CO} 2$ :s follows economic development closely. 


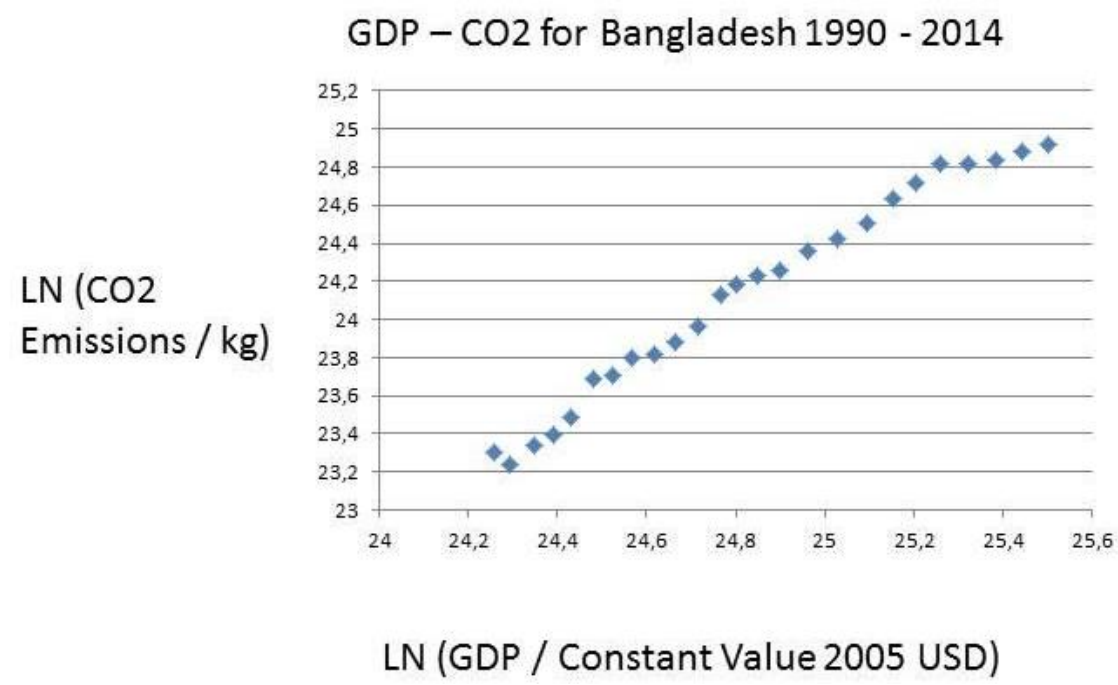

Figure 10. Bangladesh's GDP-CO@ Link $\left(y=1,43 x, R^{2}=0,98\right)$

Yet energy consumption is based on a different energy mix, compared with for instance India. Figure 11 pins down the large role of traditional renewables like wood, charcoal and dung as well as the heavy contribution of oil and gas. Bangladesh needs external support for developing modern renewables, like solar, wind and geo-thermal power sources.

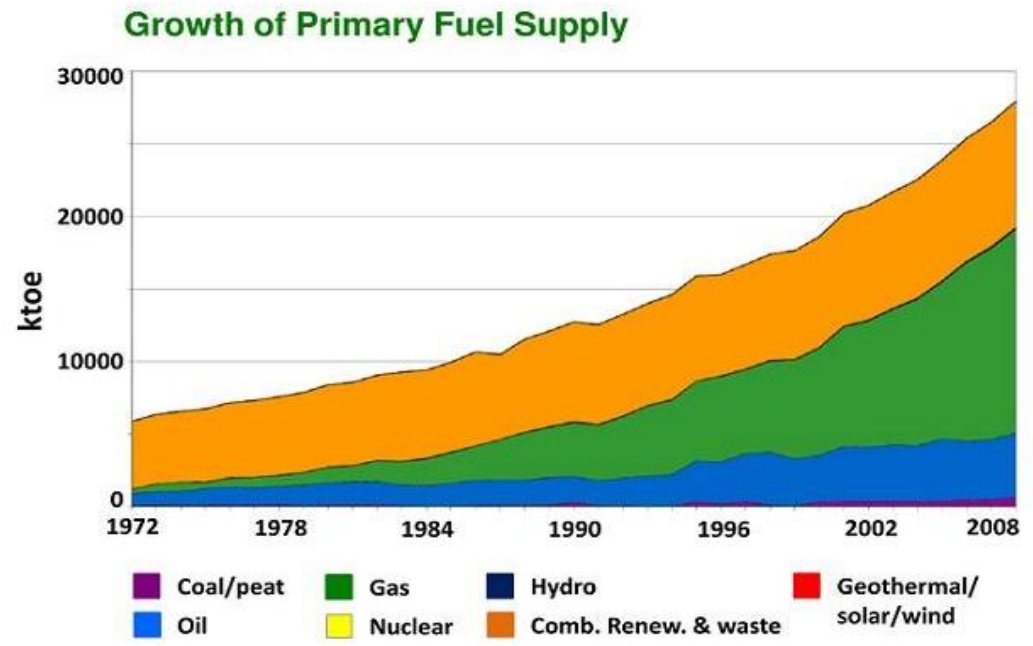

Figure 11. Growth of Primary Fuel Supply

Source: Energy Scenario in Bangladesh from 1972-2008 (Orange: Biomass, Green: Gas, Blue: Oil).

\subsubsection{Sri Lanka}

When examining small but populous Sri Lanka, one sees again the strong connection between GDP and $\mathrm{CO} 2$ :s - see Figure 12. It seems that the $\mathrm{CO} 2$ :s was halted in their expansion for some time, but now they increase again. 


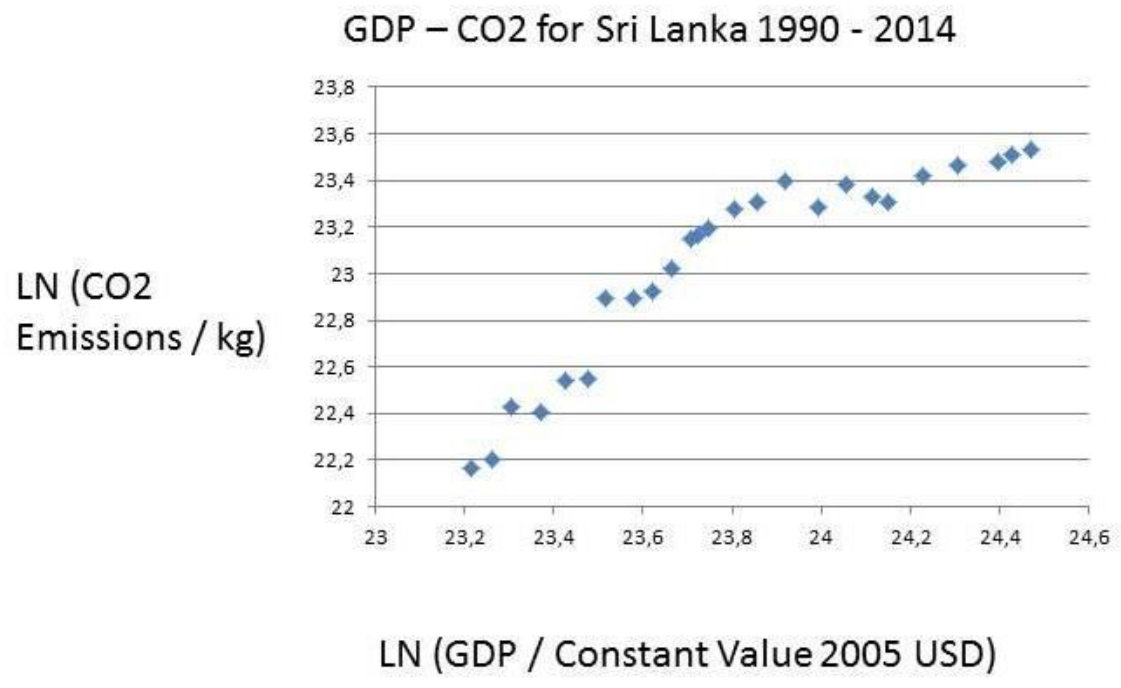

Figure 12. Sri Lanka $\left(y=1,03 x, R^{2}=0,84\right)$

In this island state, the dominant energy source is traditional renewables, which leads to deforestation and $\mathrm{CO} 2$ emissions on a large scale (Figure 13). It has been argued that the forest will grow up again, eating the carbon emissions. But it is mainly wishful thinking, as climate change and draughts make forest rehabilitation difficult.

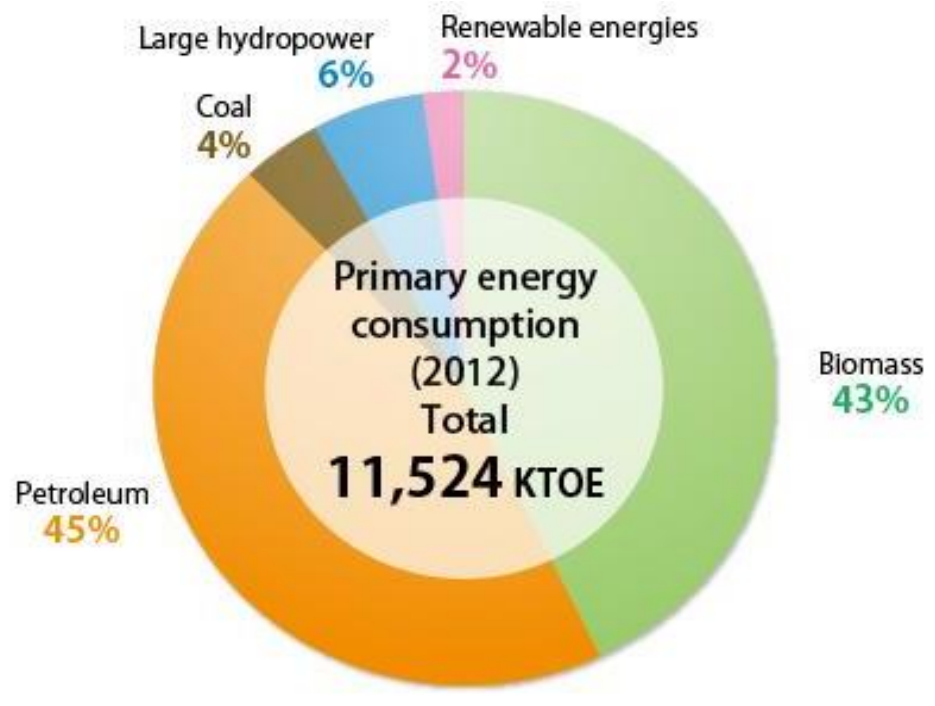

Figure 13. Sri Lanka's Energy Consumption

Source: Primary energy consumption in Sri Lanka. (2012). Retrieved from http://www.info.energy.gov.lk/

To sum up: For the poor nations in Asia with huge population holds that they cannot by themselves accomplish the objectives of COP21: Goal I: reverse current CO2 trend, Goal II: reduce by 40 per cent 
the CO2:s by 2030 and Goal III: full decarbonisation by 2075. As a matter of fact, they will need massive financial assistance from the Super Fund, which has still not been founded.

Yet, this requires that the COP21 or CO22 sets up a management structure to assist these countries involving project evaluation, policy execution and implementation, control of financial flows and outcome assessment — a gigantic task with many pitfalls involved.

\subsection{Countries with Bargaining Strategy: Risk of Sub-Optimization}

A medium income country with a not too large population can innovate, thus promoting decarbonisation by itself. But it may accomplish a more radical change with support from the Super fund, which entails extensive bargaining between the country and international governance bodies. Is a Pareto optimal outcome achievable, making Goal I and Goal II realities as outcomes?

\subsubsection{Thailand}

Figure 14 begins with Thailand that has become a rapidly developing country with increasing affluence and is besides furnishing large scale tourism a major car producer inter alia.

GDP vs. CO2 emissions Thailand 1990-2014

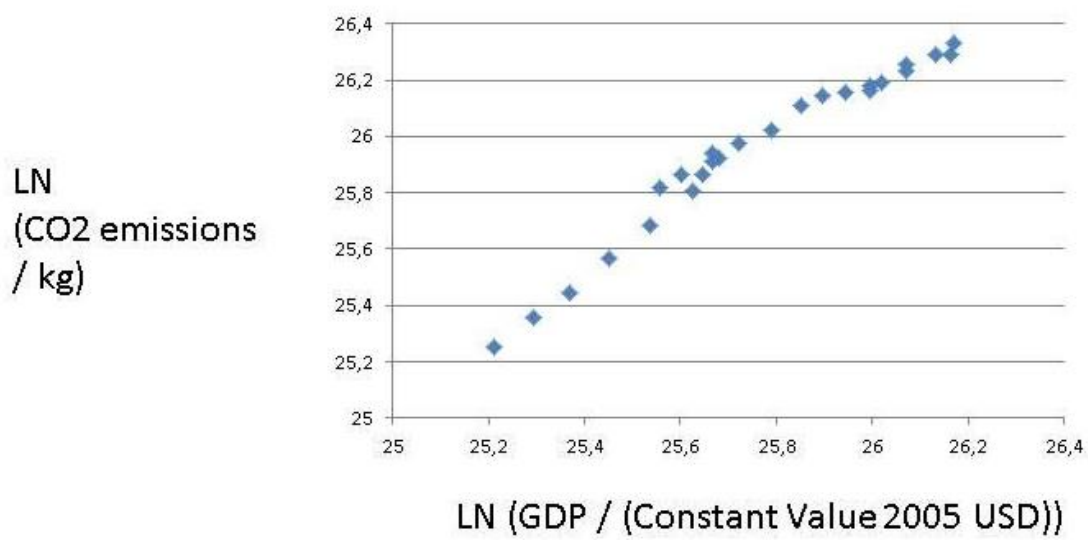

Figure 14. Thailand $\left(y=1,07 x, R^{2}=0,96\right)$

The $\mathrm{CO} 2$ emissions in Thailand are quite high, reflecting the economic advances in South East Asia. The trend is up and up. Can it be reversed without serious economic impact? Figure 15 shows the energy mix of this dynamic country, economically. 


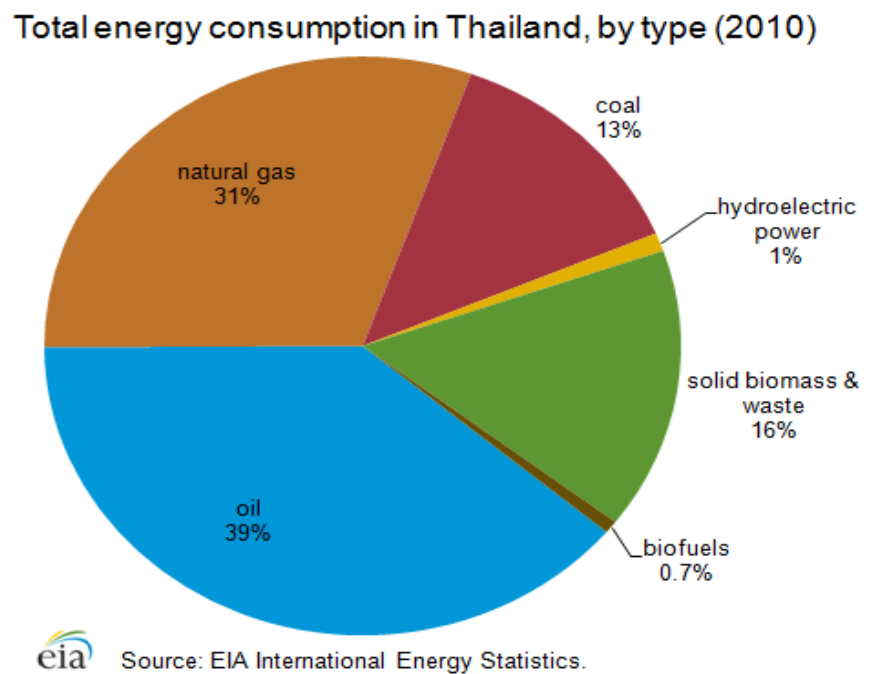

Figure 15. Thailand's Energy

The reliance upon fossil fuels is high, or over $80 \%$ of energy consumption coming from the burning of coal, oil and natural gas. Hydro power is marginal, but bio-energy plays a major role, but it is really not carbon neutral. Thailand needs to come up with far-reaching reforms of its energy sector in order to comply with COP21 objectives.

\subsubsection{Malaysia}

The overall situation — fossil fuels dependency—is the same for Malaysia as for Thailand. And the $\mathrm{CO} 2$ :s are high, following the GDP trend (Figure 16).

GDP vs. CO2 emissions Malaysia 1990-2014

$\mathrm{LN}$

(CO2 emissions

$/ \mathrm{kg}$ )

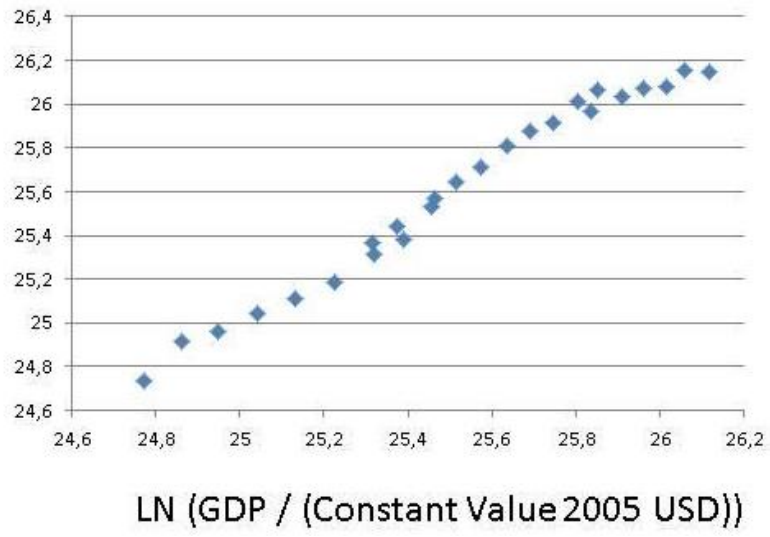

Figure 16. Malaysia $\left(y=1,13 x ; R^{2}=0,98\right)$ 
Yet, Malaysia employs energy of a very mixed bag (Figure 17), but still its emissions augment in line with economic development. There may be a planning out of the growth trend in emissions recently, but Malaysia use very little of carbon neutral energy sources. There is hydro power, but the country must move to solar and wind power rapidly.

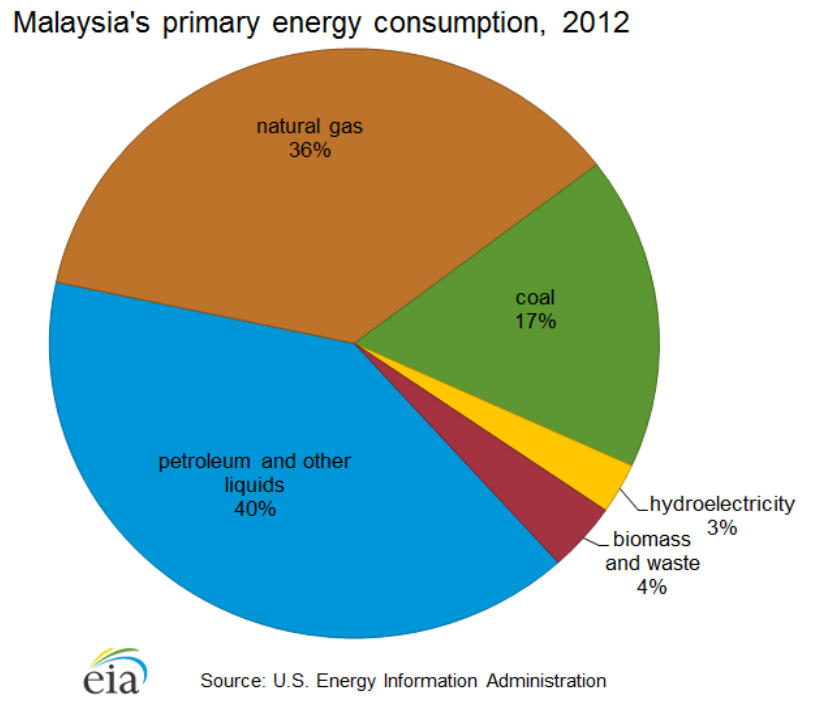

Figure 17. Malaysian Energy

Renewables are not a major element in the energy consumption mix of Malaysia, as fossil fuels dominate, but not coal luckily.

\subsubsection{Iran}

Countries may rely upon petroleum and gas mainly—see Iran (Figure 18). CO2 emissions have generally followed economic development in this giant country, although there seems to be a planning out recently, perhaps due to the international sanctions against its economy.

GDP vs. CO2 emissions Iran 1990-2014

LN

(CO2 emissions $/ \mathrm{kg})$

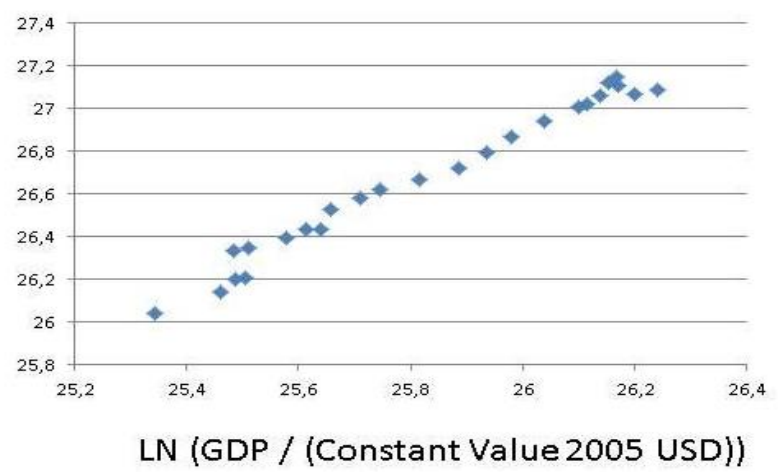

Figure 18. Iran: GDP-CO2 Link $\left(y=1,2229 x-4,91 ; R^{2}=0,98\right)$ 
Iran is together with Russia and Qatar the largest owner of natural gas deposits. But despite using coal in very small amounts, its $\mathrm{CO} 2$ emissions are high. Natural gas pollute less than oil and coal, but if released unburned it is very dangerous as a greenhouse gas. Iran relies upon its enormous resources of gas and oil (Figure 19).

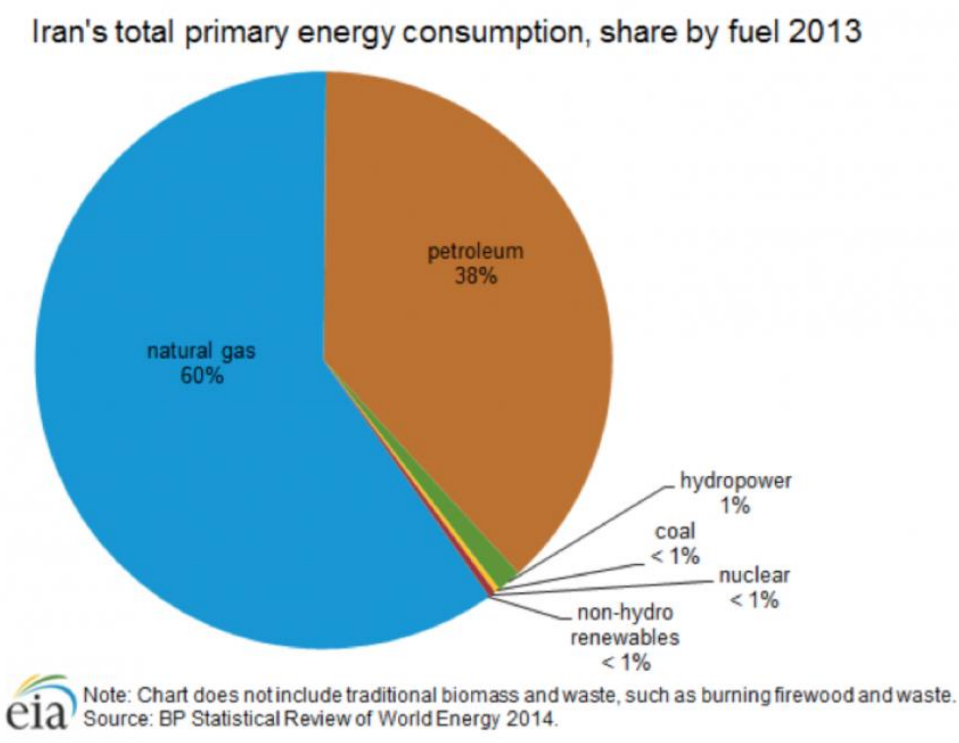

Figure 19. Iran: Energy Mix

Iran needs foreign exchange to pay for all its imports of goods and services. Using nuclear power at home and exporting more oil and gas would no doubt be profitable for the country. And it would also help Iran with the COP21 goals achievement.

\subsubsection{Vietnam and the Philippines (Figures 20-23)}

To further substantiate the argument about the $\mathrm{CO} 2$-energy conundrum that countries all over the world face, we may look at two populous nations in Asia with quickly expanding economies: Vietnam and the Philippines. They have both upward sloping trends for emissions, energy consumption and GDP, as the Kaya model entails.

Vietnam is now the perhaps most dynamic economy in Asia, after years of socialism and a planned economy. Such fast economic growth requires one thing especially, namely energy (Figure 20). 


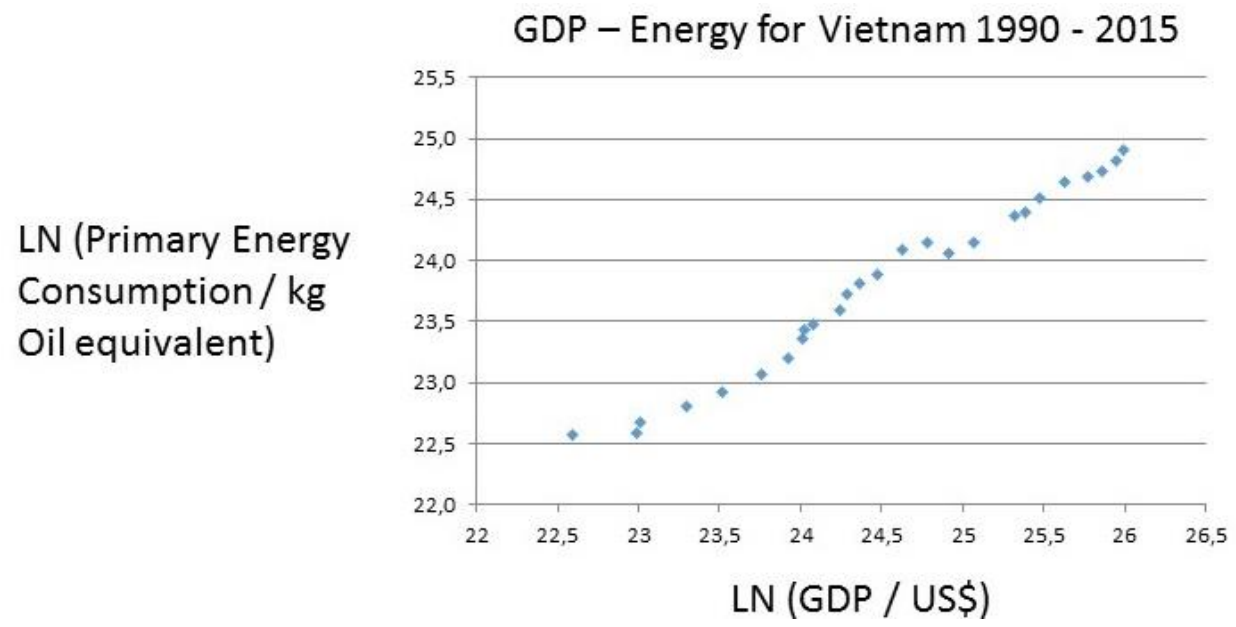

Figure 20. Vietnam: GDP and Energy $\left(y=0,74 x ; R^{2}=0,98\right)$

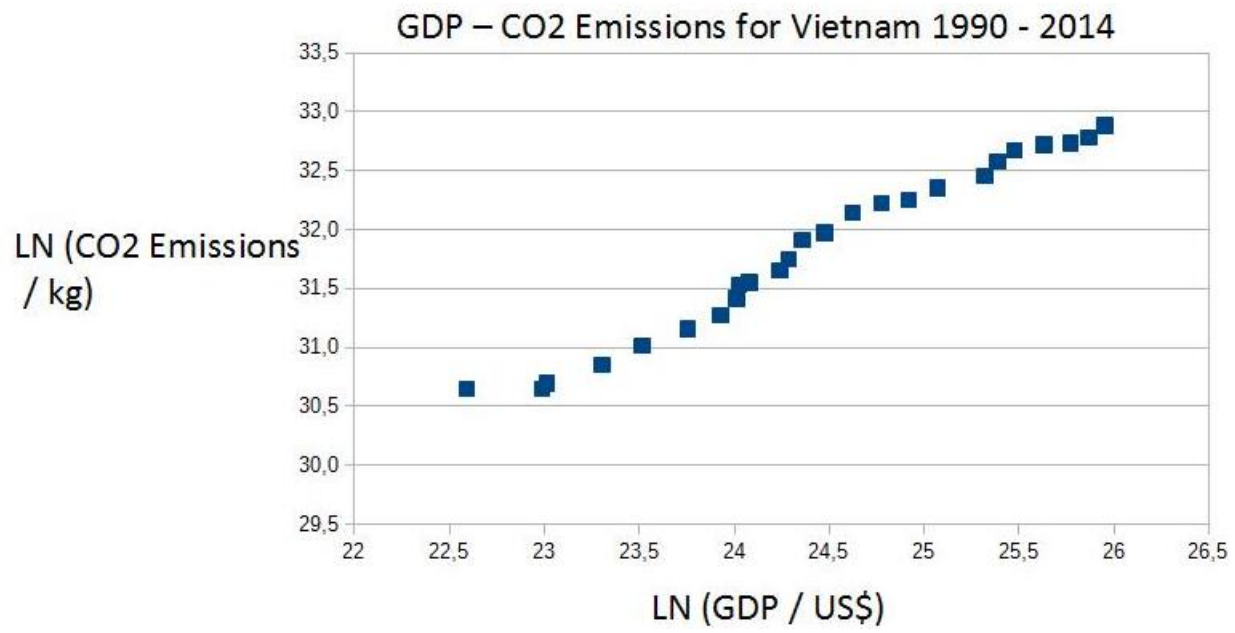

Figure 21. GDP and Emissions for Vietnam

The benefits of such an strong economic development is of course raising affluence and diminishing poverty. But the costs involve much more emissions (Figure 21).

How Vietnam is to change in order to promote the COP21 goals, Goal I and Goal II) within a short period of some 10 years, given the ambition to maintain raid economic growth, is very difficult to understand. Can really renewables do the trick? It is a highly relevant policy question, despite the massive employment of hydro power in this country.

Giant nation the Philippines is very interesting, as they claim that they can handle the implementation of the COP21 goals. This may simply be rhetoric, which is just another form of reneging upon promises. Consider first the upward sloping trend in Figure 22. 


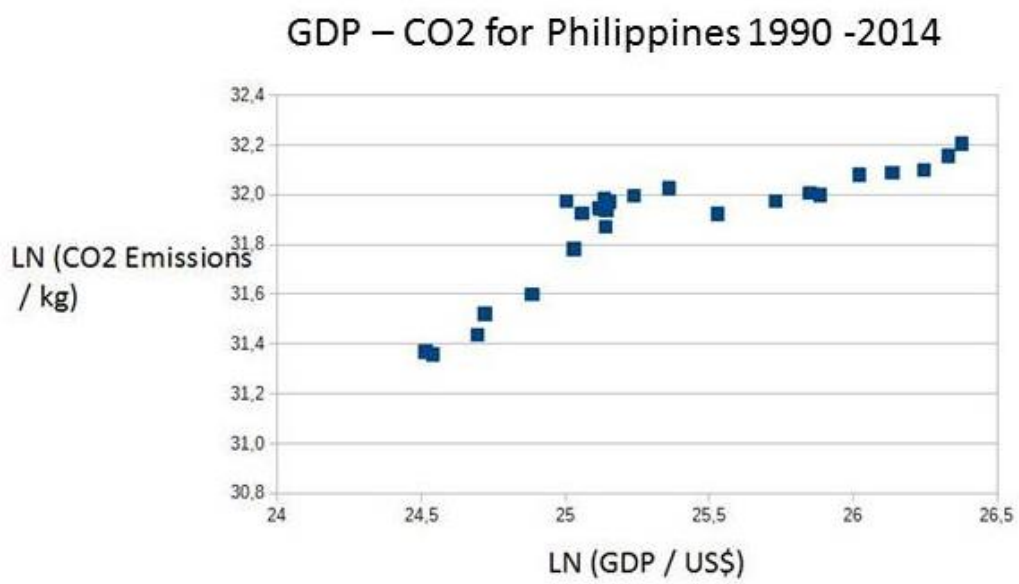

Figure 22. The Philippines

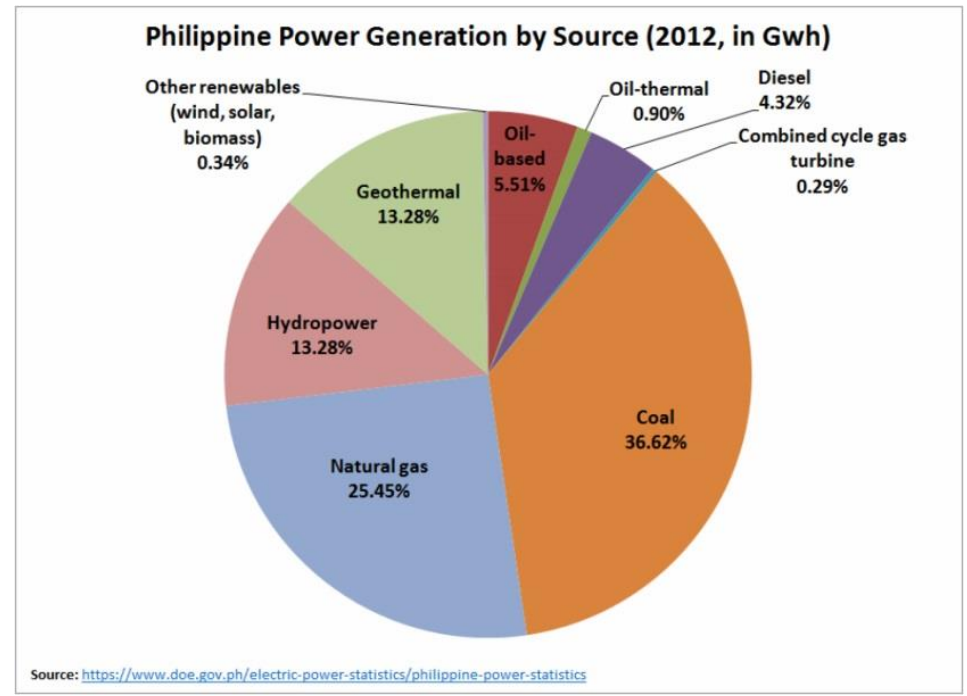

Figure 23. Energy Mix in the Philippines

The energy profile of the Philippines is actually more positive than several of the countries above, including a huge part of geo-thermal energy. Yet, fossil fuels dominate to a high 70 per cent, as in other populous and rapidly developing nations. The Philippines definitely needs help from the Super Fund.

Summary: The caching-up countries all have increasing slopes for the GDP-CO2 link, which entails profound difficulties to come for the accomplishment of Goal I in the $\mathrm{CO} 21$ project. In relation to the achievement of Goal II, one can say only note that tremendous investments have to be made by these countries in renewable energy and atomic plants, which they will find difficult to do.

\subsection{Countries with Options: Only Second Best Solutions}

A few nations do not depend upon any foreign assistance, because they are highly developed technologically and can draw upon own substantial financial resources. One may find that the 
emissions of GHG:s follows economic development closely in many countries. The basic explanation is population growth and GDP growth-more people and higher life style demands. Take the case of China, whose emissions are the largest in the world, totally speaking (Figure 24). China was a Third World country up until yesterday.

\subsubsection{China}

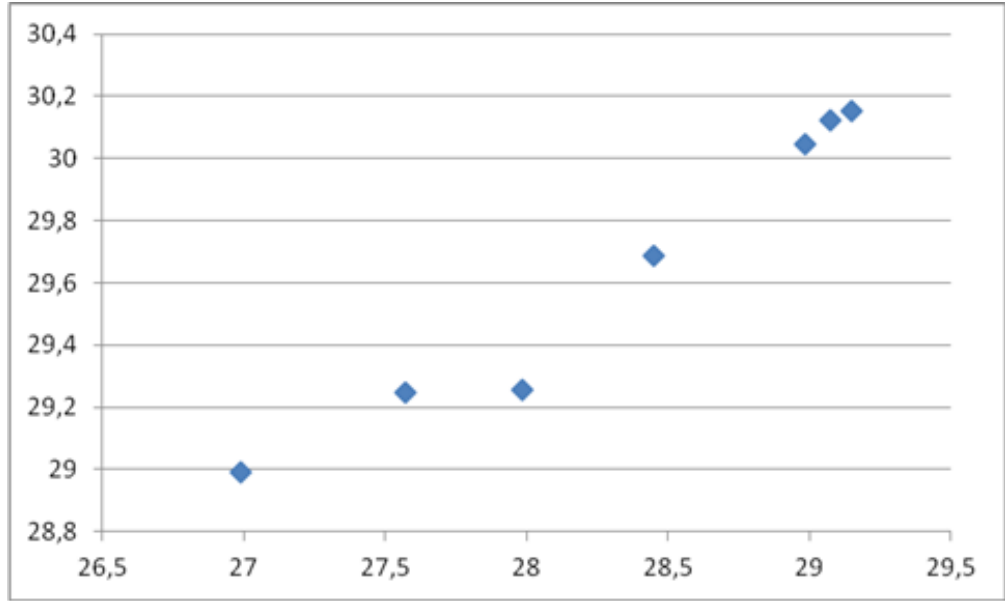

Figure 24. China: LN (GHG/Kg CO2 eq and LN (GDP/Constant Value 2005 USD)

Note. $\mathrm{GHG}=\mathrm{y}$-axis, GDP $=\mathrm{x}$-axis.

The sharp increase in GHG:s in China reflects not only the immensely rapid industrialization and urbanization of the last 30 years, but also its problematic energy mix (Figure 25).

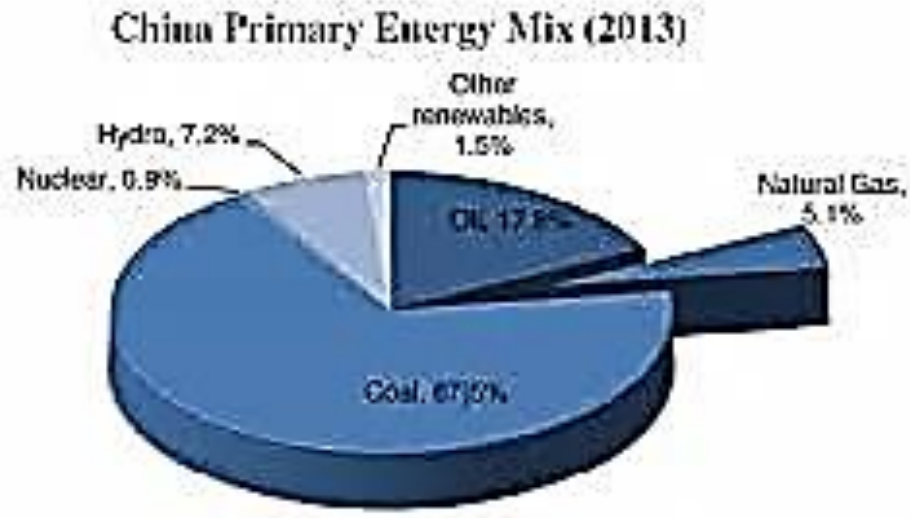

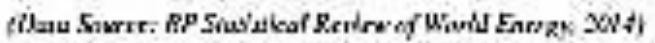

Figure 25. Chinese Energy 
Almost 70 per cent of the energy consumption comes from the burning of coal with an additional 20 per cent from other fossil fuels. The role of nuclear, hydro and other renewable energy sources is small indeed, despite new investments. This makes China very vulnerable to demands for cutting GHG emissions: other energy sources or massive installation of highly improved filters?

It should be pointed out that several small countries have much higher emissions per capita than China. This raises the enormously difficult problematic of fair cuts of emissions. Should the largest polluters per capita cut most or the biggest aggregate polluters? At COP21 this issue was resolved by the creation of a Super Fund to assist energy transition and environment protection in developing counties, as proposed by economist Stern (2007). But China can hardly ask for this form of foreign assistance. It is true that China energy consumption is changing with much more of renewables ad atomic plants. But so is also demand increasing with new and bigger cars all the time plus increased air traffic on huge new airports. Can China really cut CO2:s with 40 per cent while supply almost 50 per cent more energy power, according to plan?

\subsubsection{South Korea}

Industrial giant South Korea is very interesting frm the perspective of the COP21 Agreement, because the basic trend violates both Goal I and Goal II. An entirely different trend than that of other mature economies is to be found in South Korea (Figure 26), which has "caught up" in a stunning speed but with enormous GHG emissions.

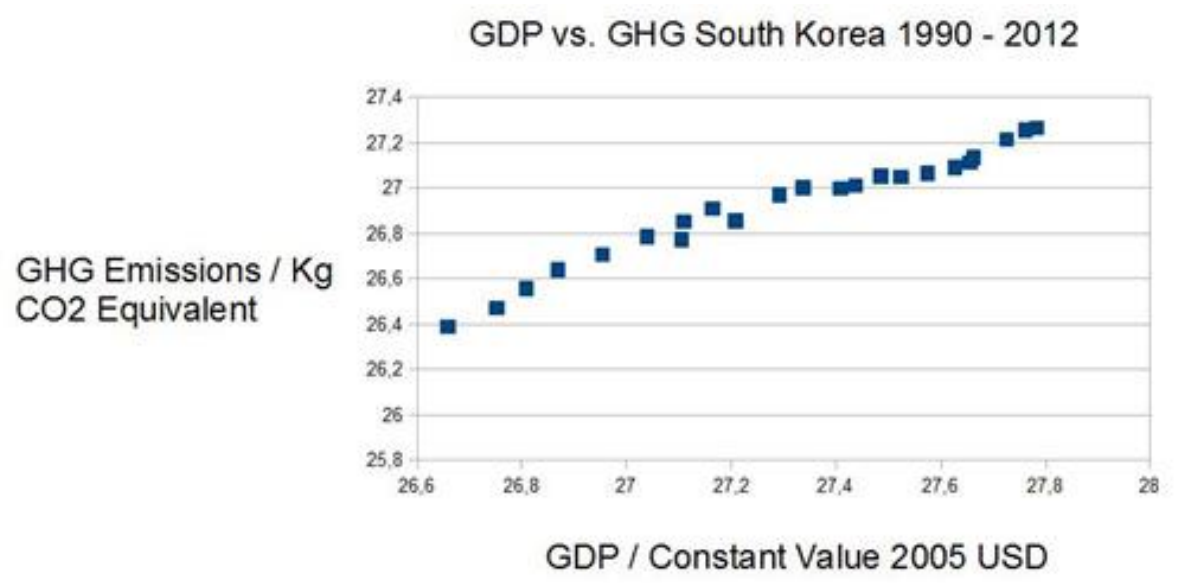

Figure 26. South Korea: LN (GHG/Kg CO2 eq and LN (GDP/Constant Value 2005 USD))

Lacking much hydro power, South Korea has turned to fossil fuels for energy purposes, almost up to 90 per cent (Figure 27). Now, it builds nuclear plants, but South Korea needs to move aggressively into solar power to reverse trends. 


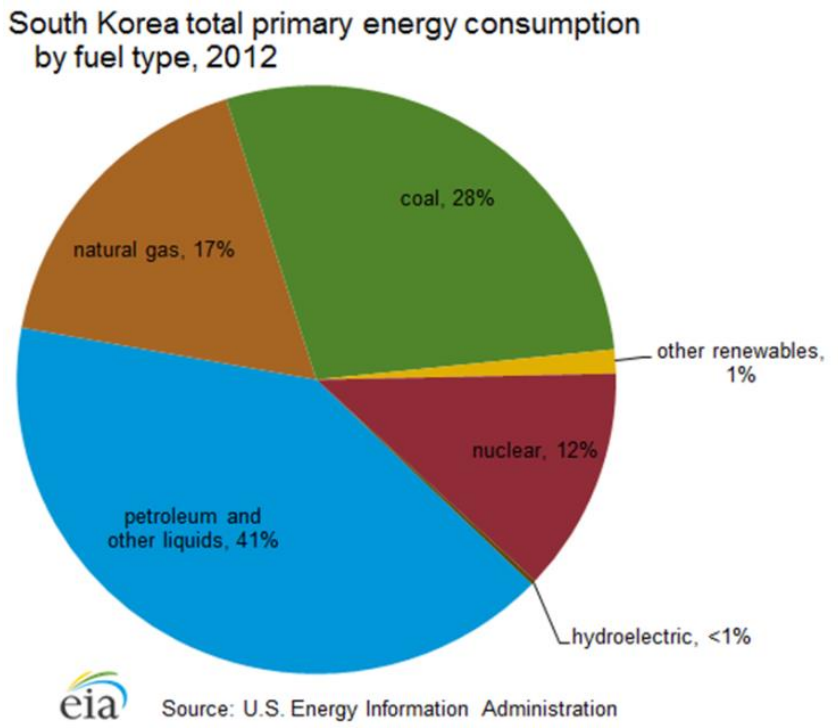

Figure 27. Energy in South Korea

It differs from China only in the reliance upon nuclear power, where the country is a world leader in plant constructions. Reducing its GHG emissions, South Korea will have to rely much more upon renewable energy sources, as well as reducing coal and oil for imported gas or LNGs.

Summing up: Neither China nor South Korea are on line for fulfilling the COP21 Goal I, as they are not reducing their emissions, like other advanced or mature economies as Japan, the EU and some EU nations. Goal II seems far away in terms of achievement for these two industrial giant, still very dependent upon fossil fuels. They innovate with renewables, but hope to consume even more energy in the coming decade.

\section{Setting up the Super Fund}

The basic argument here is that the achievement of decarbonisation according to the COP21 goals (I-III) is going to stumble upon the implications of the Kaya model, namely that $\mathrm{CO} 2$ emissions are fundamentally driven by economic forces, like the GD per capita and the size of the population besides energy and carbon intensity. To make it feasible for large poor countries to reduce $\mathrm{CO} 2$ emissions but yet maintain a decent level of economic development, the Super Fund must be made operative. Yet, it does not even "exist" in a more articulate form on paper. Countries in South Asia could not bear the costs in large scale energy transformation alone, let alone also fund policies against poverty. Several countries may accomplish superior outcomes, if funding I shared with the Super Fund.

It seems that the already existing Green Climate Fund may be transformed into the Super Fund with a budget of 100 billion a year, but it would have to be completely restructured. The management tasks involved are enormous, not to talk about the financing. The Third World will keep reminding the First 
World about this promise, which constitutes a sine-qua non.

Could the financing come from a Tobin tax or perhaps a global carbon tax? If so, global stock markets will become involved, this has not happened yet. Many First World countries are direly indebted, like the EU and the US. If financing is very uncertain, then the implementation of projects faces enormous hurdles in the form of cost efficiency, risk of corruption and embezzlement as well as conflicts between national, regional or local governments and international bodies. The implementation of the COP 21 goals requires a firm state with capacity to deliver on policies, but many Third World countries have weak or fragmented states.

Global markets are characterized by myopia, meaning that they will not react to the giant market failure than climate change tis conducive to, until it is too late. For now, it is business as usual: more air transportation, bigger cars, rapid urbanisation and a swelling demand for electricity. The use of coal is going down, which is very positive, but the number of cars is increasing in the huge countries. And giant cement constructions still come up in for instance Dubai.

\section{Conclusion}

In this comparative social science enquiry into the preconditions for respecting the promises made in the COP21 Agreement, we have found that almost all nations in the part of Asia called "l'usine du monde" develop in opposite direction. The GDP-CO2 link is upward sloping and the nergy consumption mix is dominated by fossil fuels as well as wood coal in some poor countries. A most radical transformation towards renewables and atomic power is a sine qua-non.

Global warming is said to constitute a major threat to mankind due to its impacts upon basic living conditions. To halt the climate change process requires state action from national governments and international bodies. But it is not likely to be forthcoming due to coordination failures, analysed in the social sciences. Economic development will trump environmental concerns during the 21rst century.

Thus, the global warming process is fundamentally unstoppable due to coordination failures-i.e., social sciences paradoxes. Climate change will write its message in red, resulting in climate refugees, loss of coastal areas and the destruction of healthy oceans. People will dies in large numbers, either from starvation or flooding or thirst. Economic depression will follow as demand falters. War between nations becomes unavoidable. Today state coordination is too weak and the costs involved in the implementation of the COP21 goals (I-III) too huge.

SACHS has launched the idea of a sustainable economy as a solution to the energy-emissions conundrum. However, it would entail negative economic growth or social development, which markets could not subscribe to unless forced by a deep economic recession. Reneging upon the COP21 goals is a more likely outcome with countries watching what will happen - the option of resilience. It is the only practical one, as the management tasks in stopping the global warming process are simply too gigantic. And negative economic development is not really an option, as countries dream about a 50 per 
cent augmentation in energy up to 2050, according to the standard and stylised projections.

The catastrophic scenario for the 21 rst century is more likely than the sustainable economy vision, not only because the natural sciences evidence more and more confirm the dire global warming theory, but also because the management of the COP21 is too unbelievably daunting, according to the analysis in the social sciences of policy implementation.

\section{Sources}

GDP sources:

OECD National Accounts data files.

World Bank national accounts data — http://www.data.worldbank.org

\section{GHG and energy sources:}

BP Energy Outlook, 2016.

British Petroleum Statistical Review of World Energy, 2016.

Energy Information Administration. Washington, DC.

EU Emissions Database for Global Research EDGAR—http://www.edgar.jrc.ec.europa.eu/

EU Joint Research Centre Emission Database for Global Atmospheric.

International Energy Agency. Paris.

Research—http://www.edgar.jrc.ec.europa.eu/overview.php

UN Framework Convention on Climate

Change-http://www.unfccc.int/ghg_data/ghg_data_unfccc/time_series_annex_i/items/3814.php

World Bank Data Indicators — http://www.data.worldbank.org

World Resources Institute CAIT Climate Data Explorer—http://www.cait.wri.org

\section{References}

Kaya, Y., \& Yokoburi, K. (1997). Environment, energy, and economy: Strategies for sustainability. Tokyo: United Nations University Press.

Pressman, J., \& Wildavsky, A. (1973, 1984). Implementation. Berkeley: University of California.

Sachs, J. (2015). The Age of Sustainable Development. New York: Columbia University Press. http://dx.doi.org/10.7312/sach17314

Stern, N. (2007). The Economics of Climate Change. Oxford: Oxford University Press. http://dx.doi.org/10.1017/CBO9780511817434 